\title{
Reef manta rays forage on tidally driven, high density zooplankton patches in Hanifaru Bay, Maldives
}

\author{
Asia O Armstrong ${ }^{\text {Corresp., } 1}{ }^{2}$, Guy M W Stevens ${ }^{2}$, Kathy A Townsend ${ }^{3}$, Annie Murray ${ }^{2}$, Michael B Bennett ${ }^{1}$, Amelia J \\ Armstrong ${ }^{1}$, Julian Uribe-Palomino ${ }^{4}$, Phil Hosegood ${ }^{5}$, Christine L Dudgeon ${ }^{1,3}$, Anthony J Richardson ${ }^{4,6}$ \\ ${ }^{1}$ School of Biomedical Sciences, The University of Queensland, St Lucia, Queensland, Australia \\ 2 The Manta Trust, Catemwood House, Norwood Lane, Corscombe, Dorset, United Kingdom \\ 3 School of Science, Technology, and Engineering, University of Sunshine Coast, Hervey Bay, Queensland, Australia \\ 4 Queensland Biosciences Precinct, CSIRO Oceans and Atmosphere, St Lucia, Queensland, Australia \\ 5 School of Biological and Marine Sciences, University of Plymouth, Plymouth, Devon, United Kingdom \\ 6 School of Mathematics and Physics, The University of Queensland, St Lucia, Queensland, Australia \\ Corresponding Author: Asia O Armstrong \\ Email address: asia.armstrong@uqconnect.edu.au
}

Manta rays forage for zooplankton in tropical and subtropical marine environments, which are generally nutrient-poor. Feeding often occurs at predictable locations where these large, mobile cartilaginous fishes congregate to exploit ephemeral productivity hotspots. Investigating the zooplankton dynamics that lead to such feeding aggregations remains a key question for understanding their movement ecology. The aim of this study is to investigate the feeding environment at the largest known aggregation for reef manta rays Mobula alfredi in the world. We sampled zooplankton throughout the tidal cycle, and recorded $M$. alfredi activity and behaviour, alongside environmental variables at Hanifaru Bay, Maldives. We constructed generalised linear models to investigate possible relationships between zooplankton dynamics, environmental parameters, and how they influenced $M$. alfredi abundance, behaviour, and foraging strategies. Zooplankton biomass changed rapidly throughout the tidal cycle, and $M$. alfredi feeding events were significantly related to high zooplankton biomass. Mobula alfredi switched from non-feeding to feeding

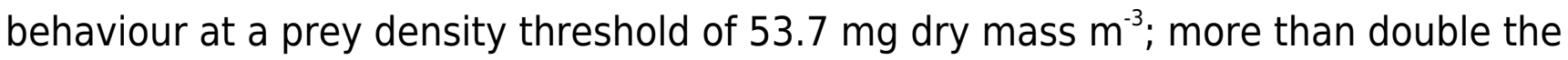
calculated density estimates needed to theoretically meet their metabolic requirements. The highest numbers of $M$. alfredi observed in Hanifaru Bay corresponded to when they were engaged in feeding behaviour. The community composition of zooplankton was different when $M$. alfredi was feeding (dominated by copepods and crustaceans) compared to when present but not feeding (more gelatinous species present than in feeding samples). The dominant zooplankton species recorded was Undinula vulgaris. This is a large-bodied calanoid copepod species that blooms in oceanic waters, suggesting offshore influences at the site. Here, we have characterised aspects of the feeding environment for Peer) reviewing PDF | (2021:04:60446:1:0:NEW 21 Jul 2021) 
M. alfredi in Hanifaru Bay and identified some of the conditions that may result in large aggregations of this threatened planktivore, and this information can help inform management of this economically important marine protected area. 


\section{Reef manta rays forage on tidally driven, high density 2 zooplankton patches in Hanifaru Bay, Maldives}

3

Asia O. Armstrong ${ }^{1}$, Guy M.W. Stevens², Kathy A. Townsend ${ }^{3}$, Annie Murray $^{2}$, Michael B. Bennett $^{1}$, Amelia J. Armstrong ${ }^{1}$, Julian Uribe-Palomino ${ }^{4}$, Phil Hosegood ${ }^{5}$, Christine L. Dudgeon ${ }^{1,3}$, and Anthony J. Richardson ${ }^{4,6}$

${ }^{1}$ School of Biomedical Sciences, The University of Queensland, St Lucia 4072, QLD, Australia ${ }^{2}$ The Manta Trust, Catemwood House, Norwood Lane, Corscombe, Dorset, DT2 0NT, UK ${ }^{3}$ School of Science, Technology, and Engineering, University of the Sunshine Coast, Hervey Bay 4655, QLD, Australia

${ }^{4}$ CSIRO Oceans and Atmosphere, Queensland Biosciences Precinct, St Lucia 4067, QLD, Australia

${ }^{5}$ School of Biological and Marine Sciences, University of Plymouth, Drake Circus, Plymouth, PL4 8AA, UK

${ }^{6}$ School of Mathematics and Physics, The University of Queensland, St Lucia 4072, QLD, Australia

Corresponding Author:

Asia Armstrong ${ }^{1}$

School of Biomedical Sciences, The University of Queensland, St Lucia 4072, QLD, Australia Email address: asia.armstrong@uqconnect.edu.au

\section{Abstract}

Manta rays forage for zooplankton in tropical and subtropical marine environments, which are generally nutrient-poor. Feeding often occurs at predictable locations where these large, mobile cartilaginous fishes congregate to exploit ephemeral productivity hotspots. Investigating the zooplankton dynamics that lead to such feeding aggregations remains a key question for understanding their movement ecology. The aim of this study is to investigate the feeding environment at the largest known aggregation for reef manta rays Mobula alfredi in the world. We sampled zooplankton throughout the tidal cycle, and recorded M. alfredi activity and behaviour, alongside environmental variables at Hanifaru Bay, Maldives. We constructed generalised linear models to investigate possible relationships between zooplankton dynamics, environmental parameters, and how they influenced M. alfredi abundance, behaviour, and foraging strategies. Zooplankton biomass changed rapidly throughout the tidal cycle, and $M$. alfredi feeding events were significantly related to high zooplankton biomass. Mobula alfredi switched from non-feeding to feeding behaviour at a prey density threshold of $53.7 \mathrm{mg}$ dry mass $\mathrm{m}^{-3}$; more than double the calculated density estimates needed to theoretically meet their 
40

41

42

43

44

45

46

47

48

49

50

51

52

53

54

55

56

57

58

59

60

61

62

63

64

65

66

67

68

69

70

71

72

73

74

75

76

77

78

79

metabolic requirements. The highest numbers of $M$. alfredi observed in Hanifaru Bay

corresponded to when they were engaged in feeding behaviour. The community composition of zooplankton was different when $M$. alfredi was feeding (dominated by copepods and crustaceans) compared to when present but not feeding (more gelatinous species present than in feeding samples). The dominant zooplankton species recorded was Undinula vulgaris. This is a large-bodied calanoid copepod species that blooms in oceanic waters, suggesting offshore influences at the site. Here, we have characterised aspects of the feeding environment for $M$. alfredi in Hanifaru Bay and identified some of the conditions that may result in large aggregations of this threatened planktivore, and this information can help inform management of this economically important marine protected area.

\section{Introduction}

Manta rays are large planktivores that inhabit tropical and subtropical waters globally, which are generally oligotrophic (Marshall et al. 2009). Therefore, to meet their metabolic needs, manta rays need to locate pulses of zooplankton productivity. Similar to other tropical planktivores, such as leatherback turtles Dermochelys coriacea (Hays et al. 2006) and whale sharks Rhincodon typus (Rohner et al. 2015), manta rays aggregate where and when conditions result in elevated local productivity (Dewar et al. 2008, Anderson et al. 2011, Jaine et al. 2012). However, these productivity 'hotspots' are ephemeral in nature and often difficult for researchers to locate and characterise (Harris et al. 2020, Harris et al. 2021), which makes the direct study of planktivore feeding ecology challenging (Sims 2008, Rohner et al. 2015).

A variety of approaches are used to study a species' diet, including stomach contents analysis, biochemical analyses, and direct observation. Two studies have recently explored the diet of manta ray species based on stomach contents: one on oceanic manta rays Mobula birostris taken in a fishery in the Philippines (Rohner et al. 2017), and one on a historic stomach sample from a reef manta ray M. alfredi collected from eastern Australia (Bennett et al. 2017). Traditionally, lethal approaches for dietary analysis, such as stomach contents analysis, are inappropriate for vulnerable marine fishes (Cortés 1997), and only offer a 'snapshot' of a species' diet (Rohner et al. 2013). Instead, biochemical approaches, including stable isotope and fatty acid analysis, are non-lethal methods that provide an integrated signal that represents the long-term diet and trophic position of species. Biochemical analysis has inferred that $M$. birostris off Ecuador derive much of its calorific intake by feeding at depth (Burgess et al. 2016), as does M. alfredi off eastern Australia (Couturier et al. 2013), and M. alfredi in the Seychelles targets pelagic zooplankton sources (Peel et al. 2019). Nevertheless, biochemical analyses lack resolution, such as identifying and quantifying preferred prey species, whereas direct observation of animal feeding allows simultaneous sampling of the feeding environment (Sims and Merrett 1997, Rohner et al. 2015, Fortune et al. 2020). 
80 Currently, the only detailed direct observation of the diet in manta rays is from an aggregation 81 site off eastern Australia, where M. alfredi was observed feeding near the surface (Armstrong et 82 al. 2016). The study found $M$. alfredi feeding events were significantly associated with greater 83 zooplankton biomass, but were not influenced by zooplankton size or species composition.

84 Further, feeding activity and zooplankton density was tidally driven at this site. Similarly, the 85 occurrence of $M$. alfredi in Komodo National Park in Indonesia was heavily influenced by tide, 86 and was considered likely to be related to feeding activity (Dewar et al. 2008). An in situ prey 87 density threshold of $11.2 \mathrm{mg} \mathrm{m}^{-3}$ was determined for $M$. alfredi foraging in eastern Australia 88 (Armstrong et al. 2016). However, a theoretical estimate of the density threshold to meet their metabolic requirements $\left(25.2 \mathrm{mg} \mathrm{m}^{-3}\right)$ suggests they require additional energy from alternate food sources, such as foraging at depth (Armstrong et al. 2016).

Manta rays exhibit behavioural plasticity in relation to their feeding environment. In eastern Australia (Jaine et al. 2012), Indonesia (Dewar et al. 2008), and the Chagos Archipelago (Harris et al. 2021), surface feeding by manta rays is frequently observed during daylight hours, and other large planktivores, such as basking sharks Cetorhinus maximus (Sims and Merrett 1997) and $R$. typus (Prebble 2018) also employ this strategy. In the Red Sea, M. alfredi swim in various circular patterns when feeding on zooplankton in shallow water (Gadig and Neto 2014). At Ningaloo Reef in Western Australia, M. alfredi is frequently observed to use a combination of feeding modes, including surface feeding, somersaulting, and bottom feeding (AOA pers. obs.). A unique strategy of "cyclone" feeding has been described at Hanifaru Bay in the Maldives, where multiple individuals manipulate the water column to create a vortex that concentrates zooplankton on which they then feed (Stevens 2016). Eight different feeding strategies have been described at this site, and have been related to prey density using a subjective visual assessment of the water column (Stevens et al. 2018). However, zooplankton density or composition has yet to be quantified in relation to these strategies. Upwards of 250 individual manta rays aggregate in Hanifaru Bay during peak feeding events, making it the largest known $M$. alfredi aggregation site in the world (Harris et al. 2020). This is therefore an ideal location to test hypotheses regarding habitat use, aggregative behaviour, feeding strategies, and zooplankton dynamics for this species.

109

110 Here, we investigate the food environment of $M$. alfredi at Hanifaru Bay, an ecologically and economically important marine protected area and core zone within a UNESCO Biosphere Reserve. Manta rays are of economic importance to both ecotourism and fisheries industries and have a conservative life history, and so identifying the foraging requirements and habitat preferences of these threatened rays should aid future conservation efforts (Stewart et al. 2018). We analyse the zooplankton dynamics (biomass, size structure, and community composition) in relation to the presence, behaviour and feeding strategies of $M$. alfredi, to improve our understanding of the feeding dynamics of this large planktivorous species. This study aims to relate changes in zooplankton biomass to $M$. alfredi behaviour; to establish a critical prey density threshold for feeding at this site, and to determine whether prey density influences the type of 
120 feeding strategy $M$. alfredi employs to exploit their prey. Further, we aim to investigate whether

121

122

123

124

125

126

127

128

129

130

131

132

133

134

135

136

137

138

139

140

141

142

143

144

145

146

147

148

149

150

151

152

153

154

155

156

157

158

159

$M$. alfredi foraging behaviour is influenced by changes in the zooplankton community composition, or size structure.

\section{Materials \& Methods}

Study Site

The Maldives has a large resident population of $M$. alfredi which undertake biannual migrations linked to the changing monsoons (seasons) within the archipelago (Anderson et al. 2011); Fig 1A). During the Southwest Monsoon, or Hulhangu (April - November), numerous M. alfredi frequent foraging aggregation sites on the eastern side of the nation's atolls (Harris et al. 2020). One site, Hanifaru Bay, is situated on the eastern edge of Baa Atoll, and attracts large feeding aggregations of this species annually (Stevens 2016, Harris et al. 2020). Hanifaru Bay is a small reef inlet (700 m long by $200 \mathrm{~m}$ wide) which forms part of a core marine protected area within the Baa Atoll UNESCO Biosphere Reserve ( $5^{\circ} 17^{\prime} \mathrm{N}, 7^{\circ} 15^{\prime} \mathrm{E}$; Fig 1B). The shallow (maximum depth $22 \mathrm{~m}$ ) inlet is periodically inundated with zooplankton-rich water. Motorised boat activity and SCUBA diving are prohibited in Hanifaru Bay due to the high numbers of manta rays and other megafauna that access the inlet (Murray et al. 2020).

\section{Data collection}

Fieldwork was conducted in the lead up to the new Moon in August 2017, under Ministry of Fisheries Permit No. (OTHR)30-D/PRIV/2017/280, and Ministry of Environment Permit No's. EPA/2017/RP-01 \& EPA/2016/PSR-M02. This time of year was chosen because strong lunar tides appear to overcome the force of the prevailing monsoonal current, drawing plankton-rich water from outside the atoll edge into Hanifaru Bay (Harris and Stevens 2021). The currents form a back eddy, trapping and concentrating plankton in this shallow reef inlet, resulting in $M$. alfredi foraging opportunities, which peak during spring and high tides (Stevens 2016, Harris and Stevens 2021). Sampling was conducted during daylight hours and across the tidal cycle from 13 - 21 August 2017. Zooplankton was collected by two people using a $200 \mu \mathrm{m}$-mesh net with a $50 \mathrm{~cm}$ diameter mouth. The net was towed by hand at the surface for a $\sim 50 \mathrm{~m}$ transect between two coral features at the eastern end of Hanifaru Bay (Fig 2A), at a speed of $22 \mathrm{~m}$ per minute. A flowmeter was fitted to the plankton net to allow calculation of the volume of water sampled. Flowmeter calibration was performed prior to the field trip in a swimming pool of known length to establish an accurate measurement of distance per flowmeter revolution.

Samples were kept on ice and fixed with $10 \%$ buffered formalin solution at the end of each day.

Each net tow was accompanied by an in-water observer recording manta ray activity in vicinity of the tow. This included: (1) manta ray abundance; (2) behaviour (Feeding, Non-feeding - when manta rays were present but not feeding, and Absent - when manta rays were not present); and (3) most common feeding strategy employed (as described in Stevens 2016; Fig 2B).

Peer] reviewing PDF | (2021:04:60446:1:0:NEW 21 Jul 2021) 
160

161

162

163

164

165

166

167

168

169

170

171

172

173

174

175

176

177

178

179

180

181

182

183

184

185

186

187

188

189

190

191

192

193

194

195

196

197

198

199

Temperature and salinity data were collected at $1 \mathrm{~s}$ intervals from a CTD unit deployed at the site for the study duration (except for $\sim 24$ hrs from $17-18$ August for battery exchange).

Temperature and salinity ranges were relatively small throughout the study $\left(28.6-29.2^{\circ} \mathrm{C}\right.$ and $34.3-35.0 \mathrm{ppt}$ respectively). These variables were excluded from the models as their inclusion resulted in missing values. Local tide data were obtained from a government representative from the Ministry of Environment.

\section{Sample processing}

Zooplankton samples were processed in the CSIRO Plankton Ecology Laboratory in Brisbane, Australia. Flowmeter readings and the area of the net mouth were used to estimate the volume of water filtered.

\section{Zooplankton biomass}

Zooplankton samples were split into two halves using a Folsom splitter (Harris et al. 2000). The first half was used to determine dry mass, with each sample oven-dried at $70^{\circ} \mathrm{C}$ for $24 \mathrm{hrs}$ prior to weighing. Zooplankton dry mass (hereafter referred to as biomass) per unit volume of filterseawater for each tow was calculated by dividing the dry mass of the sample (mg) by the volume of filtered water $\left(\mathrm{m}^{3}\right)$ :

\section{Biomass $\left(\mathrm{mg} \mathrm{m}^{-3}\right)=$ Dry mass $(\mathrm{mg}) /$ Volume of water filtered $\left(\mathrm{m}^{3}\right)$}

\section{Zooplankton identification}

The second half of the sample was used to examine size structure and community composition via a 2400 dpi ZooScan system and microscopy. The Hydroptic v3 ZooScan (EPSON Perfection V700 Flatbed) is a high resolution, waterproof scanner that digitises particles for size and biovolume measurements (Gorsky et al. 2010). An aliquot of each sample was prepared using a Stemple pipette of known volume and placed on the scanning tray. To avoid overlap, particles were manually separated. Once separated, the sample was scanned and particles were extracted into vignettes for categorisation into broad taxonomic groups (24 groups) using Plankton ID software (Version 1.2.6) and manual validation (Gorsky et al. 2010). Objects classified as sand, fibre, detritus, bubbles and shadows were excluded from further analysis (as per (Rohner et al. 2015). For visualisation, taxa that comprised $<5 \%$ of the total abundance were grouped as "other", and these included cnidaria, polychaetes, echinoderm larvae, bryozoan larvae, fish larvae, salps, and various classes of arthropods.

To investigate which species were responsible for the majority of the biomass at the site when overall biomass values in the water were high, samples were analysed taxonomically via microscopy. A subsample was prepared using a Stempel pipette, and organisms were identified and counted in a Bogorov tray using a microscope. Dominant members were identified to genus 
200 or species with assistance from trained plankton taxonomists at the CSIRO Plankton Ecology

201 Laboratory (Eriksen et al. 2019).

202

203

204

Zooplankton size structure

205

A size distribution of the sample particles, known as a Normalised Biomass Size Spectra, was

206 produced to analyse the size structure of the zooplankton community (Vandromme et al. 2012).

207 Spherical biovolume was calculated from the size measurements obtained from ZooScan. Each particle was assigned to one of 50 logarithmic size categories based on its spherical biovolume. The sum of the spherical biovolume of the particles in each size class $\left(\mathrm{mm}^{3}\right)$ was standardised by the fraction of sample scanned and the volume of water filtered $\left(\mathrm{m}^{3}\right)$, and normalised by dividing this value by the width of the size class measured in biovolume $\left(\mathrm{mm}^{3}\right)$. Both axes of the

212 Normalised Biomass Size Spectra use a logarithmic scale.

214 To investigate potential drivers of zooplankton abundance and $M$. alfredi visits to Hanifaru Bay, we constructed generalised linear models (GLMs) using R (R Core Team 2019). Separate analyses were conducted for two response variables: (i) Zooplankton biomass $\left(\mathrm{mg} \mathrm{m}^{-3}\right)$, with a

217 Gamma error structure and log-link function; and (ii) Manta ray abundance (number of $M$.

218 alfredi observed during zooplankton sampling), with a negative binomial error structure and log219 link function (Poisson error structure was overdispersed). We visually inspected diagnostic plots 220 to assess assumptions of homogeneity of variance and normality. Independent variables in both 221 models were Tide (hours from high tide) and Behaviour (Feeding, Non-feeding and Absent). To 222 account for the circular nature of Tide ( 12-hr cycle), the variable was transformed using a

223

224

225

226

227

228

229

230

231

232

233

234

235

236

237

238 truncated Fourier series (a harmonic function of sines and cosines). This ensures that the cyclical nature of this variable is captured, while guaranteeing that the response values predicted at the extremes of the variable range are the same (i.e., the same prediction for Zooplankton biomass or Count at times of 0 and 24 hours). For the Manta ray abundance model, the Behaviour variable was reduced to two categories - namely Feeding and Non-feeding, and Zooplankton biomass $\left(\mathrm{mg} \mathrm{m}^{-3}\right)$ was included as an independent variable. Models were plotted on the response scale using the package "visreg" in R (Breheny and Burchett 2017).

\section{Critical thresholds for feeding behaviour and strategy}

We assessed whether there might be a critical threshold for $M$. alfredi feeding - i.e., a level above which the likelihood of feeding increases dramatically. We thus used a GLM with a binomial error structure to analyse manta ray behavioural response (Non-Feeding $=0$, Feeding $=$ 1) in relation to zooplankton biomass $\left(\mathrm{mg} \mathrm{m}^{-3}\right)$ as a predictor. The critical density threshold was taken as the zooplankton biomass at which the proportion of feeding was 0.5 . A theoretical prey density threshold was plotted for comparison, based on findings by Armstrong et al. (2016).

Their study assumed general morphometrics (average disc width of $3.5 \mathrm{~m}$, mouth opening of 0.3 
$239 \mathrm{~m}$, and mass of $100 \mathrm{~kg}$ ) and swim speeds ( 2 knots when feeding) for $M$. alfredi. These

240 assumptions are also applicable in the current study.

241

242 Feeding samples were categorised into either Solo feeding (Straight, Surface and Somersault) or

243 Group feeding (Piggy-back and Chain) based on the most common strategy observed in the

244 manta rays (Stevens 2016). A GLM with a binomial error structure was used to analyse manta

245

246

247

248

249

250

251

252

253

254

255

256

257

258

259

260

261

262

263

264

265

266

267

268

269

270

271

272

273

274

275

276

277 ray feeding strategy response $($ Solo $=0$, Group $=1)$ in relation to zooplankton biomass $\left(\mathrm{mg} \mathrm{m}^{-3}\right)$ as a predictor. The critical density threshold was taken as the zooplankton biomass at which the proportion of Group feeding was 0.5 .

\section{Zooplankton community analysis}

To determine how different the zooplankton communities were for the $M$. alfredi behaviours (Feeding or Non-Feeding), non-metric multidimensional scaling was used based on abundance counts of the different taxonomic groups from the Zooscan analysis. The Bray Curtis distance measure was used because it is unaffected by joint absences of taxonomic groups in samples. To account for abundance of certain taxa, data were transformed using a root transformation. To test for differences in community composition between M. alfredi behaviours (Feeding and NonFeeding), we performed an adonis analysis, a multivariate analysis of variance. Both the adonis and non-metric multidimensional scaling were conducted using the "vegan" package in R (Oksanen et al. 2007).

\section{Results}

A total of 77 zooplankton samples were collected (Feeding $=33$, Non-feeding $=22$, and Absent $=22$ ) over a period of nine days. Overall zooplankton biomass ranged between 0.7 and $643.1 \mathrm{mg}$ $\mathrm{m}^{-3}$ (mean $\left.=90.7, \mathrm{SD}=130.9\right)$. For manta ray behaviours, zooplankton biomass for Feeding samples ranged between 7.3 and $593.6 \mathrm{mg} \mathrm{m}^{-3}$, for Non-feeding samples between 1.1 and 175.6 $\mathrm{mg} \mathrm{m}^{-3}$, and for absent samples between 0.7 - and $643.1 \mathrm{mg} \mathrm{m}^{-3}$.

GLM analyses showed that Zooplankton biomass in Hanifaru Bay was significantly related to Tide and Behaviour (Fig 3). Zooplankton biomass was greatest just following high tide ( $\mathrm{t}=$ $3.83, \mathrm{p}=0.0003$, Fig $3 \mathrm{~A}$ ), and $M$. alfred $i$ was more commonly observed feeding when zooplankton biomass was higher $(\mathrm{t}=-2.83, \mathrm{p}=0.006$, Fig $3 \mathrm{~B})$.

Manta ray behaviour was significantly related to zooplankton biomass $(z=3.08, p=0.002)$, with a prey density threshold of $53.7 \mathrm{mg} \mathrm{m}^{-3}$ calculated for feeding M. alfredi (Fig 4).

Manta ray abundance was significantly related to Behaviour ( $z=-5.55, \mathrm{p}=0.000000003$; Fig 5), with more M. alfredi individuals present when they were feeding in Hanifaru Bay. Tide and 
278 Biomass did not significantly relate to manta ray abundance. Manta ray abundance ranged

279 between 0 and 25 individuals.

280

281

282

283

284

285

286

287

288

289

290

291

292

293

294

295

296

297

298

299

300

301

302

303

304

305

306

307

308

309

310

311

312

313

\section{Discussion}

315 Summary

316 Zooplankton concentrations influence the number of $M$. alfredi present and their observed

317 behaviour in Hanifaru Bay. Rapid changes in zooplankton are observed across the tidal cycle, 
318 and $M$. alfredi feed when biomass reaches a critical density which is higher than predicted to

319

320

321

322

323

324

325

326

327

328

329

330

331

332

333

334

335

336

337

338

339

340

341

342

343

344

345

346

347

348

349

350

351

352

353

354

355

356

357

meet their theoretical metabolic requirements. Mobula alfredi foraging occurs when the zooplankton community is dominated by calanoid copepods, and feeding is less likely when there are greater numbers of gelatinous taxa (such as chaetognaths or eggs). Taxonomic analysis reveals that the large-bodied copepod, Undinula vulgaris, dominates the zooplankton environment at Hanifaru Bay, suggesting oceanic incursions may play an important role in bringing zooplankton to this small reef inlet.

\section{Tidal influence on zooplankton density and manta ray foraging}

Manta rays feed when zooplankton biomass is high, which is typically observed on the high to ebbing tide at Hanifaru Bay. Oceanographic investigations in Hanifaru Bay suggest tidal currents draw zooplankton into the shallow reef systems of the atoll, where they become trapped inside due to a back-eddy mechanism created by the unique shape of the reef system and the combination of the lunar and monsoon currents (Hosegood pers comms). Tides are known to influence the distribution and abundance of zooplankton around island inlets in the Great Barrier Reef (Alldredge and Hamner 1980), and have been shown to influence manta ray feeding behaviour at aggregation sites in Indonesia (Dewar et al. 2008), eastern Australia (Armstrong et al. 2016), and the Chagos Archipelago (Harris et al. 2021). Therefore, short-term in situ observations of zooplankton concentrations in relation to tidal cycles and manta ray behaviour can help inform when M. alfredi is likely to be observed in Hanifaru Bay.

\section{Animal movements and productivity hotspots}

Large planktivores seeking to exploit ephemeral food sources in surface waters are likely to respond to currents and water movements that concentrate zooplankton. Cetorhinus maximus forage along thermal fronts (Sims and Quayle 1998), R. typus targets regions of upwelling (Ryan et al. 2017), and surface foraging in M. alfredi is often tidally driven (Dewar et al. 2008, Armstrong et al. 2016). In conjunction with responding to physical oceanographic cues, animals that seek patchily distributed prey sources are also likely to congregate in areas where they have previously encountered energetically rewarding prey abundances, resulting in larger numbers of animals in reliable foraging regions. For example, $M$. alfredi predictably switches to the downcurrent side of the atolls in the Maldives in response to monsoonal winds and primary productivity (Harris et al. 2020). Area-restricted search theory predicts that animals will remain localised in areas where they have a higher probability of encountering prey (Bailey et al. 2019), and this perhaps explains why some M. alfredi individuals remain in Hanifaru Bay when not feeding. This location also has two cleaning stations used by M. alfredi (Stevens 2016), and it is hypothesised manta rays will frequent cleaning stations in close proximity to foraging opportunities (Armstrong et al. 2021). Manta rays in Palmyra Atoll used area-restricted searching when adjacent to ledges or channels with high plankton concentrations, but their movements were more random at larger spatial scales (Papastamatiou et al. 2012). Area-restricted searching has also been observed in two dolphin species (Tursiops truncatus and Delphinus delphis) in 
358

359

360

361

362

363

364

365

366

367

368

369

370

371

372

373

374

375

376

377

378

379

380

381

382

383

384

385

386

387

388

389

390

391

392

393

394

395

396

397

areas of high prey availability, and where they have had previous successful foraging experience, suggesting memory plays a role in their movement ecology (Bailey et al. 2019). For M. alfredi, the apparent preference for returning to the same cleaning stations over time (Armstrong et al. 2021), suggests they may form a cognitive map of shallow reef environments, and this is likely the case for known productivity hotspots as well.

\section{High critical feeding threshold for manta rays at Hanifaru Bay}

The critical prey density threshold for $M$. alfredi feeding in Hanifaru Bay $\left(53.7 \mathrm{mg} \mathrm{m}^{-3}\right)$ is more than four times higher than that in east Australia where M. alfredi feeds $\left(11.2 \mathrm{mg} \mathrm{m}^{-3}\right.$; Armstrong et al. 2016), and in east Africa where R. typus feeds (12.4 mg m-3; Rohner et al. 2015). It is also double the theoretical prey density threshold calculated to meet the metabolic requirements for M. alfredi (25.2 $\mathrm{mg} \mathrm{m}^{-3}$; Armstrong et al. 2016), which may explain why this site hosts such a large feeding aggregation of this species. However, these large planktivorous elasmobranchs are assumed to feed in the mesopelagic layer (Couturier et al. 2013, Burgess et al. 2016), so an understanding of the prey densities available at these depths is required to gauge the relative importance of aggregations sites such as Hanifaru Bay in meeting these species' daily energetic requirements. Sampling zooplankton at depth remains a logistical challenge for researchers, but with technological advances, such as satellite tags equipped with accelerometer data loggers, and unmanned video submersibles (Stewart et al. 2018), these inferences can be better investigated.

\section{Manta ray feeding strategies}

In the current study, plasticity in M. alfredi feeding strategies in response to changes in prey biomass in Hanifaru Bay is not supported. This contrasts with work previously conducted in Hanifaru Bay that found manta rays were significantly more likely to employ group feeding strategies as prey density increased (Stevens 2016). The previous work was based on a qualitative visual index for prey density, with data obtained over a long time period ( $>5$ years) and included aggregations upwards of 150 animals. However, we did see that when zooplankton biomass values were very high, over $200 \mathrm{mg} \mathrm{m}^{-3}$, that only Group feeding strategies were used, and no Solo feeding was seen. But in either scenario, it is uncertain whether the observations are due to true cooperative feeding strategies, or simply that coordinate movements reduce collisions with other manta rays (Stevens 2016).

\section{Zooplankton composition and size}

Differences in the composition of the zooplankton community were observed between M. alfredi Feeding and Non-feeding events, and M. alfredi was observed feeding when the overall biovolume of zooplankton was greater. Calanoid copepods dominate the zooplankton community for manta rays at Hanifaru Bay during the time of the study. This is similar to findings for $M$. birostris at Isla de la Plata, Ecuador, where zooplankton samples collected during feeding and non-feeding events were dominated by calanoid copepods, but also cyclopoid copepods (Burgess 2017). The diet of mobulids (M. japonica, M. thurstoni, M. tarapacana, and M. birostris) in the 
398

399

400

401

402

403

404

405

406

407

408

409

410

411

412

413

414

415

416

417

418

419

420

421

422

423

424

425

426

427

428

429

430

431

432

433

434

435

436

437

Philippines is more diverse, with euphausiid krill dominating, but also records from stomach content analysis of squid, fish and copepods (Rohner et al. 2017). Investigations into foraging aggregations of $C$. maximus off Plymouth in the UK have also revealed the dominance of copepods during feeding events, with threefold increases in this taxa reported (Sims 1999). In contrast, the food environment at $R$. typus feeding aggregations appear to be more diverse, with $R$. typus feeding on sergestid shrimps, fish spawn, calanoid copepods, and small bait fish (Motta et al. 2010, Fox et al. 2013, Rohner et al. 2015). These findings suggest that the food environment for large planktivores feeding in predominately tropical or sub-tropical waters is varied, and is likely driven by pulses in productivity, rather than particular taxa.

Undinula vulgaris is the most prominent species observed in zooplankton samples from Hanifaru Bay. It is a key species in tropical areas due to its large size and tendency to swarm in high numbers, making it a good food resource for planktivorous fishes (Alvarez-Cadena et al. 1998). This species has been observed at numerous large planktivore feeding aggregation sites, including those visited by M. alfredi in eastern Australia (Couturier et al. 2013, Armstrong et al. 2016), R. typus in the Gulf of Tadjoura, Djibouti (Boldrocchi et al. 2018), both M. birostris and R. typus in the Gulf of California (Notarbartolo-di-Sciara 1988, Lavaniegos et al. 2012), and both M. alfredi and R. typus in the Philippines (Canencia and Metillo 2013, Yap-Dejeto et al. 2018). Undinula vulgaris is considered an indicator of the influence of neritic-oceanic waters in reef environments, and its local distribution can suggest oceanic water sources (Alvarez-Cadena et al. 1998). Further investigation into the ecology of $U$. vulgaris in tropical environments may aid our understanding of how vital swarms of this species are for supporting large tropical planktivores, and whether their distribution and abundance is likely to be impacted by a rapidly changing climate.

\section{Caveats to zooplankton sampling}

There were three main limitations in the sampling design of the current study. First, as boat engines are prohibited in the area, towing of the plankton was done by hand and this resulted in tow speeds slower than recommended ( $22 \mathrm{~m} \mathrm{vs} 60 \mathrm{~m}$ per minute) for minimising captureavoidance by larger zooplankton (Harris et al. 2000). However, the use of a net with a relatively large mouth area (50 cm diameter) would help mitigate this. Further, the use of slower towing speeds (Davies and Beckley 2010) and a relatively large mesh size for tropical waters (200 $\mu \mathrm{m}$; Eriksen et al. 2019) should reduce the pressure wave from the towed net, and thus reduce concerns about net avoidance by zooplankton. Second, zooplankton sampling was limited to surface waters. This could influence the findings, particularly in relation to investigating the zooplankton dynamics when manta rays are employing different feeding strategies. For example, somersault feeding and cyclone feeding strategies do not necessarily occur in surface waters. This issue could be overcome with the use of drop nets, vertical free-fall nets that sample on the way down with weighted rings for propulsion (Eriksen et al. 2019), to provide coverage throughout the water column. Lastly, it is likely our relatively short sampling duration failed to 
438

439

440

441

442

443

444

445

446

447

448

449

450

451

452

453

454

455

456

457

458

459

460

461

462

463

464

465

466

467

468

469

470

471

472

473

474

475

476

477

detect group feeding dynamics, and our results could suffer from small sample size. More work needs to be done to assess whether the presence of higher zooplankton biomass is positively correlated with group feeding events. In particular, higher sampling replication of the eight different feeding strategies is required to tease apart how these relate to zooplankton dynamics. One of the key issues for sampling design is that the magnitude and exact timing of the biggest feeding events each season is somewhat variable (Harris and Stevens 2021). This highlights the need for studying multiple feeding events in a consistent way to distil the general pattern. To further examine the zooplankton and manta ray foraging dynamics at this site, we suggest a future sample size at least double the current study, and attempts should be made to sample larger feeding aggregations (50+ manta rays).

\section{Conclusions}

Identifying important foraging opportunities for vulnerable species such as manta rays remains a goal for implementing effective conservation strategies for the species. Here, we conducted the first analysis of the food environment for $M$. alfredi at Hanifaru Bay, and highlighted the importance of tidal regimes and high zooplankton density in driving $M$. alfredi aggregations at this site. Conducting high resolution investigations into the dietary basis of aggregations can help inform drivers of species movements and habitat preferences. This can be challenging in remote locations where resources are sparse, and where fieldwork is logistically difficult (i.e., handtowing for zooplankton is seldom recorded in methods), which may provide an explanation as to why most feeding studies for marine megafauna have only superficially investigated zooplankton dynamics. This study failed to record the zooplankton dynamics during a mass feeding aggregation at this site, and so our findings are suggestive of what can be observed at this location, but they may not provide the whole picture. Longer term sampling, and more targeted methodologies that allow for sampling of zooplankton throughout the water column, will help elucidate what leads to mass feeding aggregations and the role of different feeding strategies for $M$. alfredi at this site. Nevertheless, the findings here have emphasised the importance of this site as a foraging ground for large aggregations of $M$. alfredi. To maintain this natural phenomenon, we suggest a number of management considerations. For example: (1) Implementing a code of conduct for tourism interactions with manta rays would help ensure human activities do not interfere with manta ray foraging activity; and (2) To preserve the zooplankton community, the oceanographic conditions of the region should not be altered (i.e. no dredging or alterations to natural sand movements). Climate change also poses an unknown risk to this aggregation site, as our findings suggest the zooplankton originate elsewhere and could be altered by predicted temperature shifts. Here, we have determined the importance of zooplankton dynamics in driving aggregative behaviour of $M$. alfredi at the large aggregation site in Hanifaru Bay, and this information can help inform management of this ecologically and economically important marine protected area and core zone within a UNESCO Biosphere Reserve.

Peer) reviewing PDF | (2021:04:60446:1:0:NEW 21 Jul 2021) 
478

479

480

481

482

483

484

485

486

487

488

489

490

491

492

493

494

495

496

497

498

499

500

501

502

503

504

505

506

507

508

509

510

511

512

513

514

515

516

517

518

519

520

\section{Acknowledgements}

We would like to acknowledge the logistic and field assistance from the team at the Manta Trust, specifically Niv Froman and Tam Sawers. Special thanks to Stephanie Venables for assistance in the field. Thanks to the Plankton Ecology Lab in Brisbane for their expert assistance, namely Frank Coman. We would like to thank Simon Pierce and David Sims for providing valuable feedback on the manuscript.

\section{References}

Alldredge, A. L., and W. M. Hamner. 1980. Recurring aggregation of zooplankton by a tidal current. Estuarine and Coastal Marine Science 10:31-37.

Alvarez-Cadena, J. N., E. Suárez-Morales, and R. Gasca. 1998. Copepod Assemblages from a Reef-Related Environment in the Mexican Caribbean Sea. Crustaceana 71:411-433.

Anderson, R. C., M. S. Adam, and J. I. Goes. 2011. From monsoons to mantas: seasonal distribution of Manta alfredi in the Maldives. Fisheries Oceanography 20:104-113.

Armstrong, A. O., A. J. Armstrong, M. B. Bennett, A. J. Richardson, K. A. Townsend, J. D. Everett, G. C. Hays, H. Pederson, and C. L. Dudgeon. 2021. Mutualism promotes site selection in a large marine planktivore. Ecology and Evolution.

Armstrong, A. O., A. J. Armstrong, F. R. Jaine, L. I. Couturier, K. Fiora, J. Uribe-Palomino, S. J. Weeks, K. A. Townsend, M. B. Bennett, and A. J. Richardson. 2016. Prey Density Threshold and Tidal Influence on Reef Manta Ray Foraging at an Aggregation Site on the Great Barrier Reef. PLoS ONE 11:e0153393.

Bailey, H., V. Lyubchich, J. Wingfield, A. Fandel, A. Garrod, and A. Rice. 2019. Empirical evidence that large marine predator foraging behavior is consistent with area-restricted search theory. Ecology 100:e02743.

Bennett, M., F. Coman, K. Townsend, L. Couturier, F. Jaine, and A. Richardson. 2017. A historical and contemporary consideration of the diet of the reef manta ray (Manta alfredi) from the Great Barrier Reef, Australia. Marine and Freshwater Research 68:993997.

Boldrocchi, G., Y. M. Omar, D. Rowat, and R. Bettinetti. 2018. First results on zooplankton community composition and contamination by some persistent organic pollutants in the Gulf of Tadjoura (Djibouti). Science of The Total Environment 627:812-821.

Breheny, P., and W. Burchett. 2017. Visualization of regression models using visreg. R J. 9:56. Burgess, K. 2017. Feeding ecology and habitat use of the giant manta ray Manta birostris at a key aggregation site off mainland Ecuador. The University of Queensland.

Burgess, K. B., L. I. Couturier, A. D. Marshall, A. J. Richardson, S. J. Weeks, and M. B. Bennett. 2016. Manta birostris, predator of the deep? Insight into the diet of the giant manta ray through stable isotope analysis. Royal Society Open Science 3:160717.

Canencia, M. O. P., and E. B. Metillo. 2013. Spatio-Temporal Distribution, Abundance, and Lipid Content of Calanid Copepod Species in an Upwelling Area and an Estuarine Plume 
521

522

523

524

525

526

527

528

529

530

531

532

533

534

535

536

537

538

539

540

541

542

543

544

545

546

547

548

549

550

551

552

553

554

555

556

557

558

559

560

561

562

563

564

in Northern Mindanao, Philippines. IAMURE International Journal of Ecology and Conservation 8:164.

Cortés, E. 1997. A critical review of methods of studying fish feeding based on analysis of stomach contents: application to elasmobranch fishes. Canadian Journal of Fisheries and Aquatic Sciences 54:726-738.

Couturier, L. I. E., C. A. Rohner, A. J. Richardson, A. D. Marshall, F. R. A. Jaine, M. B. Bennett, K. A. Townsend, S. J. Weeks, and P. D. Nichols. 2013. Stable Isotope and Signature Fatty Acid Analyses Suggest Reef Manta Rays Feed on Demersal Zooplankton. PLoS ONE 8: 77152.

Davies, C., and L. Beckley. 2010. Zooplankton from the inshore waters of Christmas Island (Indian Ocean) with reference to larvae of the red land crab, Gecarcoidea natalis. Journal of the Royal Society of Western Australia 93:43-50.

Dewar, H., P. Mous, M. Domeier, A. Muljadi, J. Pet, and J. Whitty. 2008. Movements and site fidelity of the giant manta ray, Manta birostris, in the Komodo Marine Park, Indonesia. Marine Biology (Berlin) 155:121-133.

Eriksen, R. S., C. H. Davies, P. Bonham, F. E. Coman, S. Edgar, F. R. McEnnulty, D. McLeod, M. J. Miller, W. Rochester, and A. Slotwinski. 2019. Australia's long-term plankton observations: the integrated marine observing system national reference station network. Frontiers in Marine Science 6:161.

Fortune, S. M., S. H. Ferguson, A. W. Trites, J. M. Hudson, and M. F. Baumgartner. 2020. Bowhead whales use two foraging strategies in response to fine-scale differences in zooplankton vertical distribution. Scientific reports 10:1-18.

Fox, S., I. Foisy, R. De La Parra Venegas, B. Galván Pastoriza, R. Graham, E. Hoffmayer, J. Holmberg, and S. Pierce. 2013. Population structure and residency of whale sharks Rhincodon typus at Utila, Bay Islands, Honduras. Journal of Fish Biology 83:574-587.

Gadig, O. B. F., and D. G. Neto. 2014. Notes on the feeding behaviour and swimming pattern of Manta alfredi (Chondrichthyes, Mobulidae) in the Red Sea. acta ethologica:119-122.

Gorsky, G., M. D. Ohman, M. Picheral, S. Gasparini, L. Stemmann, J.-B. Romagnan, A. Cawood, S. Pesant, C. García-Comas, and F. Prejger. 2010. Digital zooplankton image analysis using the ZooScan integrated system. Journal of Plankton Research 32:285-303.

Harris, J. L., P. Hosegood, E. Robinson, C. B. Embling, S. Hilbourne, and G. M. W. Stevens. 2021. Fine-scale oceanographic drivers of reef manta ray (Mobula alfredi) visitation patterns at a feeding aggregation site. Ecology and Evolution.

Harris, J. L., P. K. McGregor, Y. Oates, and G. M. Stevens. 2020. Gone with the wind: Seasonal distribution and habitat use by the reef manta ray (Mobula alfredi) in the Maldives, implications for conservation. Aquatic Conservation: Marine and Freshwater Ecosystems 30:1649-1664.

Harris, J. L., and G. M. Stevens. 2021. Environmental drivers of reef manta ray (Mobula alfredi) visitation patterns to key aggregation habitats in the Maldives. PLoS ONE 16:e0252470.

Harris, R., P. Wiebe, J. Lenz, H.-R. Skjoldal, and M. Huntley. 2000. ICES zooplankton methodology manual. Academic Press.

Hays, G. C., V. J. Hobson, J. D. Metcalfe, D. Righton, and D. W. Sims. 2006. Flexible foraging movements of leatherback turtles across the North Atlantic Ocean. Ecology 87:26472656. 
565

566

567

568

569

570

571

572

573

574

575

576

577

578

579

580

581

582

583

584

585

586

587

588

589

590

591

592

593

594

595

596

597

598

599

600

601

602

603

604

605

606

607

608

609

610

Jaine, F. R. A., L. I. E. Couturier, S. J. Weeks, K. A. Townsend, M. B. Bennett, K. Fiora, and A. J. Richardson. 2012. When Giants Turn Up: Sighting Trends, Environmental Influences and Habitat Use of the Manta Ray Manta alfredi at a Coral Reef. PLoS ONE 7:e46170.

Lavaniegos, B., G. Heckel, and P. L. de Guevara. 2012. Seasonal variability of copepods and cladocerans in Bahía de los Ángeles (Gulf of California) and importance of Acartia clausi as food for whale sharks. Ciencias Marinas 38:11-30.

Marshall, A. D., L. J. V. Compagno, and M. B. Bennett. 2009. Redescription of the genus Manta with resurrection of Manta alfredi (Krefft, 1868) (Chondrichthyes; Myliobatoidei; Mobulidae). Zootaxa 2301:1-28.

Motta, P. J., M. Maslanka, R. E. Hueter, R. L. Davis, R. De la Parra, S. L. Mulvany, M. L. Habegger, J. A. Strother, K. R. Mara, and J. M. Gardiner. 2010. Feeding anatomy, filterfeeding rate, and diet of whale sharks Rhincodon typus during surface ram filter feeding off the Yucatan Peninsula, Mexico. Zoology 113:199-212.

Murray, A., E. Garrud, I. Ender, K. Lee-Brooks, R. Atkins, R. Lynam, K. Arnold, C. Roberts, J. Hawkins, and G. Stevens. 2020. Protecting the million-dollar mantas; creating an evidence-based code of conduct for manta ray tourism interactions. Journal of Ecotourism 19:132-147.

Notarbartolo-di-Sciara, G. 1988. Natural history of the rays of the genus Mobula in the Gulf of California. Fishery Bulletin 86:45-66.

Oksanen, J., R. Kindt, P. Legendre, B. O’Hara, M. H. H. Stevens, M. J. Oksanen, and M. Suggests. 2007. The vegan package. Community ecology package.

Papastamatiou, Y. P., P. A. DeSalles, and D. J. McCauley. 2012. Area-restricted searching by manta rays and their response to spatial scale in lagoon habitats. Marine Ecology Progress Series 456:233-244.

Peel, L., R. Daly, C. Keating, G. Stevens, S. Collin, and M. Meekan. 2019. Stable isotope analyses reveal unique trophic role of reef manta rays ( Mobula alfredi ) at a remote coral reef. Royal Society Open Science 6:190599.

Prebble, C. M. E. 2018. Residency and trophic ecology of juvenile whale sharks (Rhincodon typus) in the Western Indian Ocean. University of Southampton.

R Core Team. 2019. R: A language and environment for statistical computing., R Foundation for Statistical Computing, Vienna, Austria.

Rohner, C. A., A. J. Armstrong, S. J. Pierce, C. E. M. Prebble, F. E. Cagua, J. E. M. Cochran, M. L. Berumen, and A. J. Richardson. 2015. Whale sharks target dense prey patches of sergestid shrimp off Tanzania. Journal of Plankton Research:fbv010.

Rohner, C. A., K. B. Burgess, J. M. Rambahiniarison, J. D. Stewart, A. Ponzo, and A. J. Richardson. 2017. Mobulid rays feed on euphausiids in the Bohol Sea. Royal Society Open Science 4:161060.

Rohner, C. A., L. I. E. Couturier, A. J. Richardson, S. J. Pierce, and C. Preddle. 2013. Diet of whale sharks Rhincodon typus inferred from stomach content and signature fatty acid analyses. Marine Ecology Progress Series 10.

Ryan, J. P., J. R. Green, E. Espinoza, and A. R. Hearn. 2017. Association of whale sharks (Rhincodon typus) with thermo-biological frontal systems of the eastern tropical Pacific. PLoS ONE 12:e0182599.

Sims, D. W. 1999. Threshold foraging behaviour of basking sharks on zooplankton: life on an energetic knife-edge? Proceedings of the Royal Society of London. Series B: Biological Sciences 266: 1437-1443.

Peer) reviewing PDF | (2021:04:60446:1:0:NEW 21 Jul 2021) 
611 Sims, D. W. 2008. Chapter 3 Sieving a Living: A Review of the Biology, Ecology and

612

613

614

615

616

617

618

619

620

621

622

623

624

625

626

627

628

629

630

631

632

633

634

635

636

637
Conservation Status of the Plankton-Feeding Basking Shark Cetorhinus maximus. Pages 171-220 in W. S. David, editor. Advances in marine biology. Academic Press.

Sims, D. W., and D. A. Merrett. 1997. Determination of zooplankton characteristics in the presence of surface feeding basking sharks Cetorhinus maximus. Marine Ecology Progress Series 158:297-302.

Sims, D. W., and V. A. Quayle. 1998. Selective foraging behaviour of basking sharks on zooplankton in a small-scale front. Nature 393:460-464.

Stevens, G., D. Fernando, M. Dando, and G. N. Di Sciara. 2018. Guide to the Manta and Devil Rays of the World. Princeton University Press.

Stevens, G. M. W. 2016. Conservation and Population Ecology of Manta Rays in the Maldives. University of York.

Stewart, J. D., F. R. A. Jaine, A. J. Armstrong, A. O. Armstrong, M. B. Bennett, K. B. Burgess, L. I. E. Couturier, D. A. Croll, M. R. Cronin, M. H. Deakos, C. L. Dudgeon, D. Fernando, N. Froman, E. S. Germanov, M. A. Hall, S. Hinojosa-Alvarez, J. E. Hosegood, T. Kashiwagi, B. J. L. Laglbauer, N. Lezama-Ochoa, A. D. Marshall, F. McGregor, G. Notarbartolo di Sciara, M. D. Palacios, L. R. Peel, A. J. Richardson, R. D. Rubin, K. A. Townsend, S. K. Venables, and G. M. W. Stevens. 2018. Research Priorities to Support Effective Manta and Devil Ray Conservation. Frontiers in Marine Science 5.

Vandromme, P., L. Stemmann, C. Garcìa-Comas, L. Berline, X. Sun, and G. Gorsky. 2012. Assessing biases in computing size spectra of automatically classified zooplankton from imaging systems: A case study with the ZooScan integrated system. Methods in Oceanography 1:3-21.

Yap-Dejeto, L., A. Cera, J. Labaja, J. D. Palermo, A. Ponzo, and G. Araujo. 2018. Observations of Microzooplankton in the Vicinity of Whale Shark Rhincodon typus Aggregation Sites in Oslob, Cebu and Pintuyan, S. Leyte, Philippines. J. of Nat. Sci 22:61-77. 


\section{Figure 1}

Study site in Hanifaru Bay in Baa Atoll, The Maldives.

A) Map of The Maldives, black star indicates location of Hanifaru Bay in Baa Atoll; and B)

Satellite image of Hanifaru Island and Lagoon, with key study site of Hanifaru Bay and prevailing current regimes (Credit: Copernicus Sentinel data 2020, accessed via USGS EarthExplorer and processed by AJA).

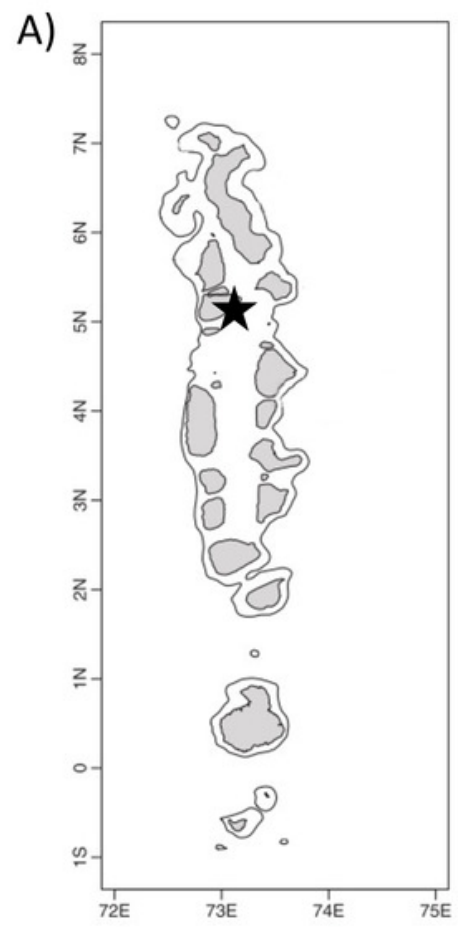

B)

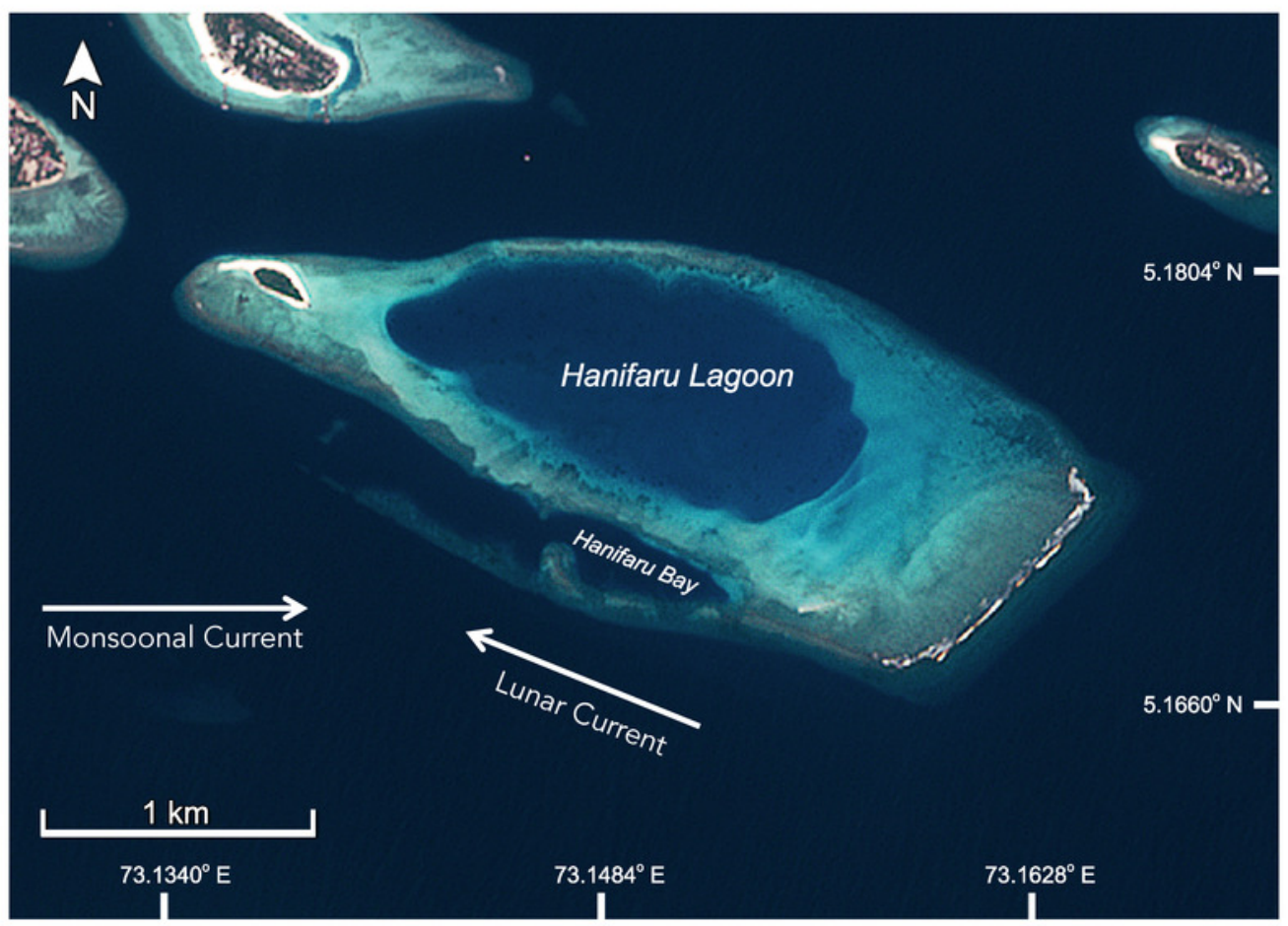


Figure 2

Zooplankton sampling and reef manta ray Mobula alfredi feeding strategies.

A) Zooplankton samples were collected by two snorkellers surface swimming a $200 \mu \mathrm{m}$-mesh net with flowmeter for $\sim 50 \mathrm{~m}$; and B) Ethogram of feeding strategies: i) Straight, ii) Surface, iii) Chain, iv) Piggy-back, v) Somersault, vi) Cyclone, vii) Sideways, and viii) Bottom (Illustration credit: Marc Dando). 


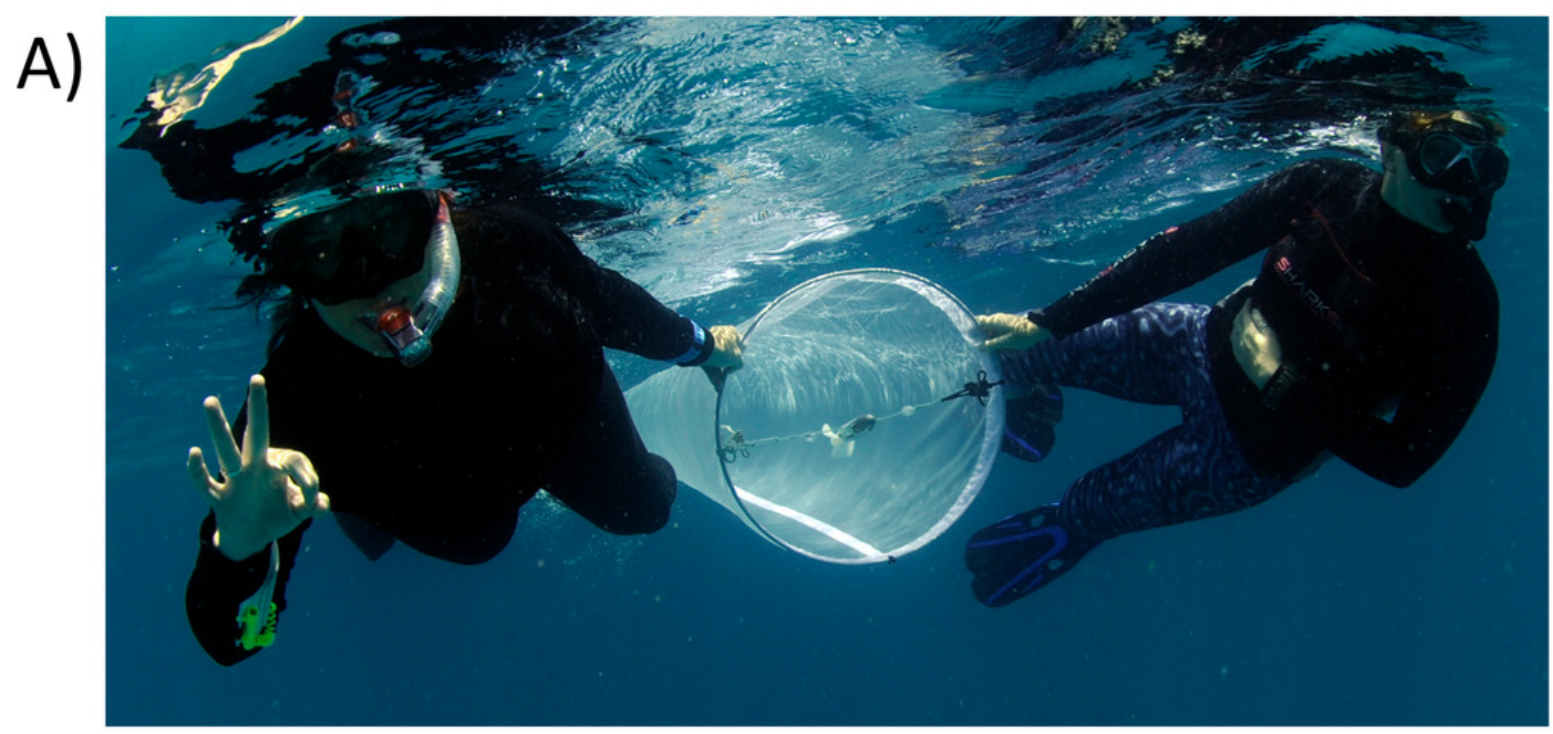

B)
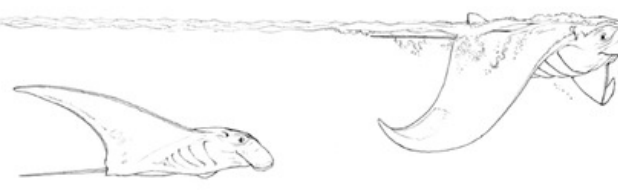

ii) Surface

i) Straight
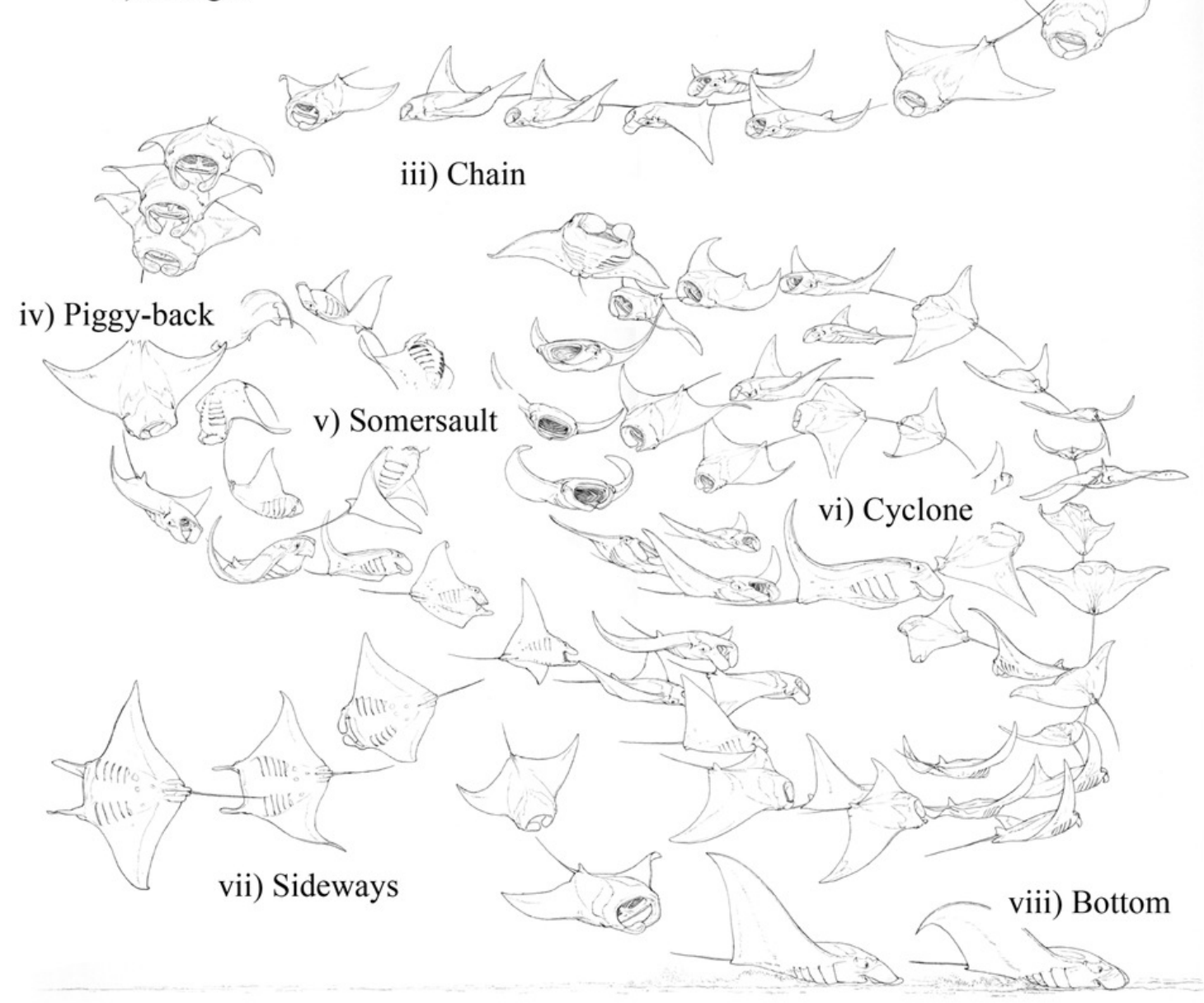
Figure 3

Zooplankton biomass in Hanifaru Bay, Maldives.

Raw data including A) Scatterplot of Zooplankton biomass and Tide (hours from high tide) and B) Boxplot of Zooplankton biomass and Manta ray behaviour (Feeding, Non-feeding and Absent). Model output of significant independent variables related to Zooplankton biomass, including C) Tide (hours from high tide) and Manta ray behaviour. Biomass is on the response scale, with $95 \%$ confidence intervals.

A)

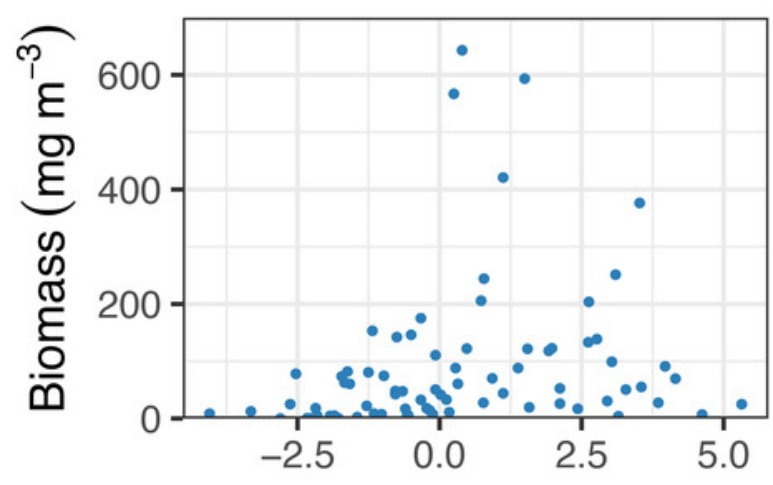

C)

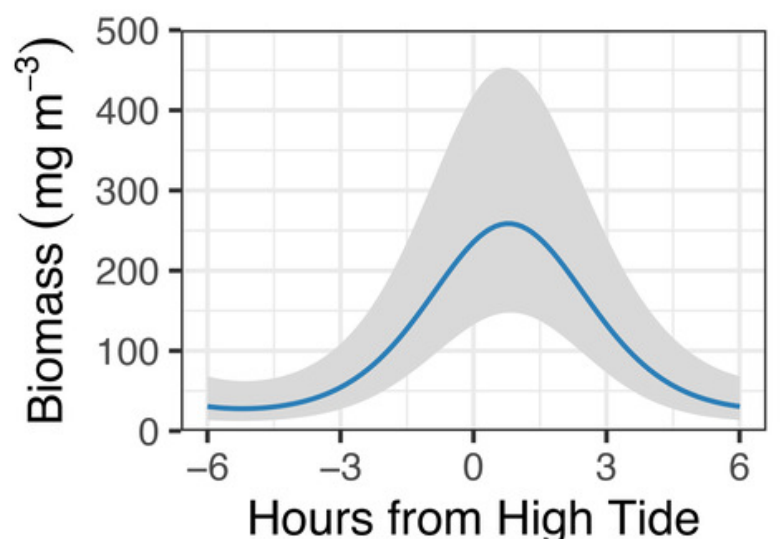

B)

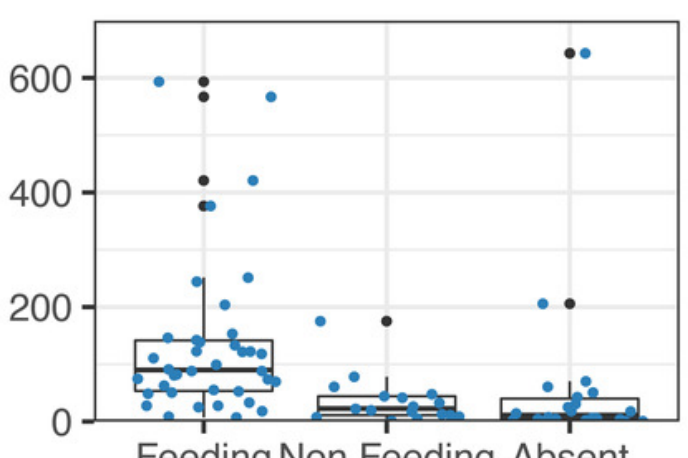

Feeding Non Feeding Absent

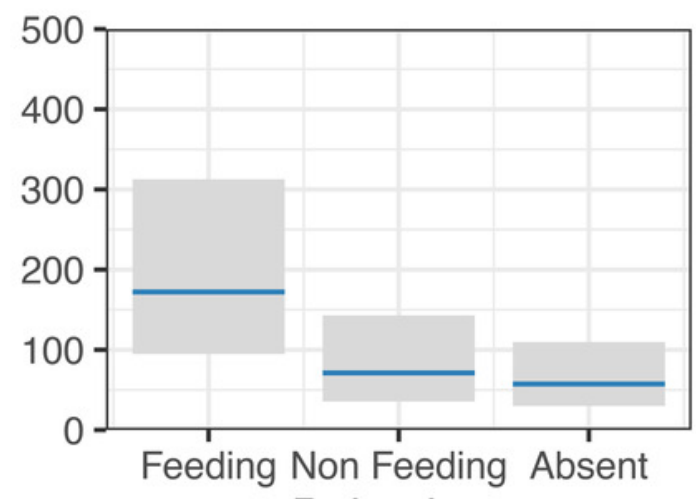

Behaviour 
Figure 4

Critical prey density foraging threshold.

Logistic regression of reef manta ray Mobula alfredi behaviour (Feeding $=1$, Non-feeding $=$ 0 ) in relation to zooplankton biomass $\left(\mathrm{mg} \mathrm{m}^{-3}\right)$. The black dashed line represents the critical prey density threshold of zooplankton biomass required to trigger manta ray feeding from in situ sampling (53.7 $\mathrm{mg} \mathrm{m}^{-3}$ ), and the red dashed line represents the theoretical prey density threshold calculated to meet the metabolic requirements of foraging M. alfredi $\left(25.2 \mathrm{mg} \mathrm{m}^{-3}\right.$; Armstrong et al. 2016 ).

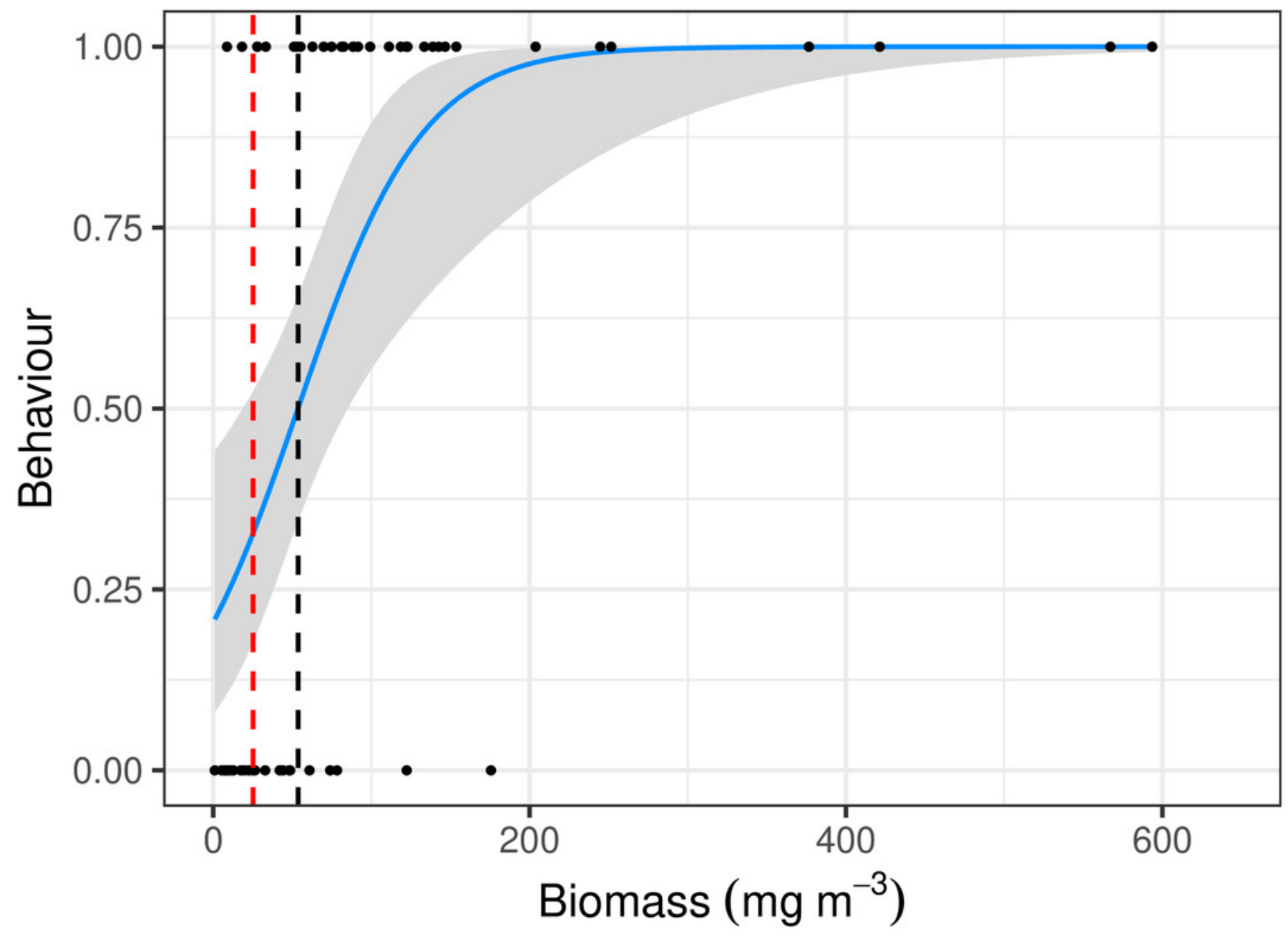


Figure 5

Reef manta ray Mobula alfredi abundance in Hanifaru Bay, Maldives.

A) Raw data boxplot of Manta ray abundance and Manta ray behaviour (Feeding and Nonfeeding); and B) Model output of significant variable related to greater manta ray numbers in Hanifaru Bay. Manta ray abundance is on the response scale, with $95 \%$ confidence intervals.

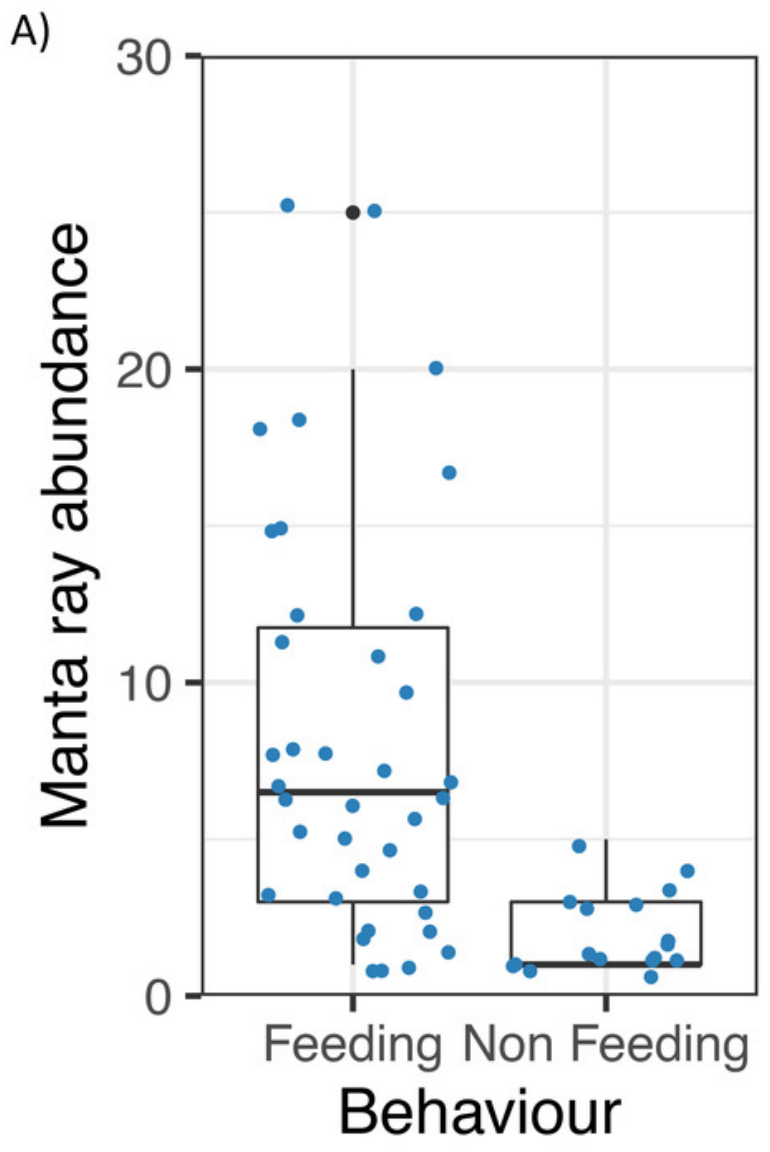

B)

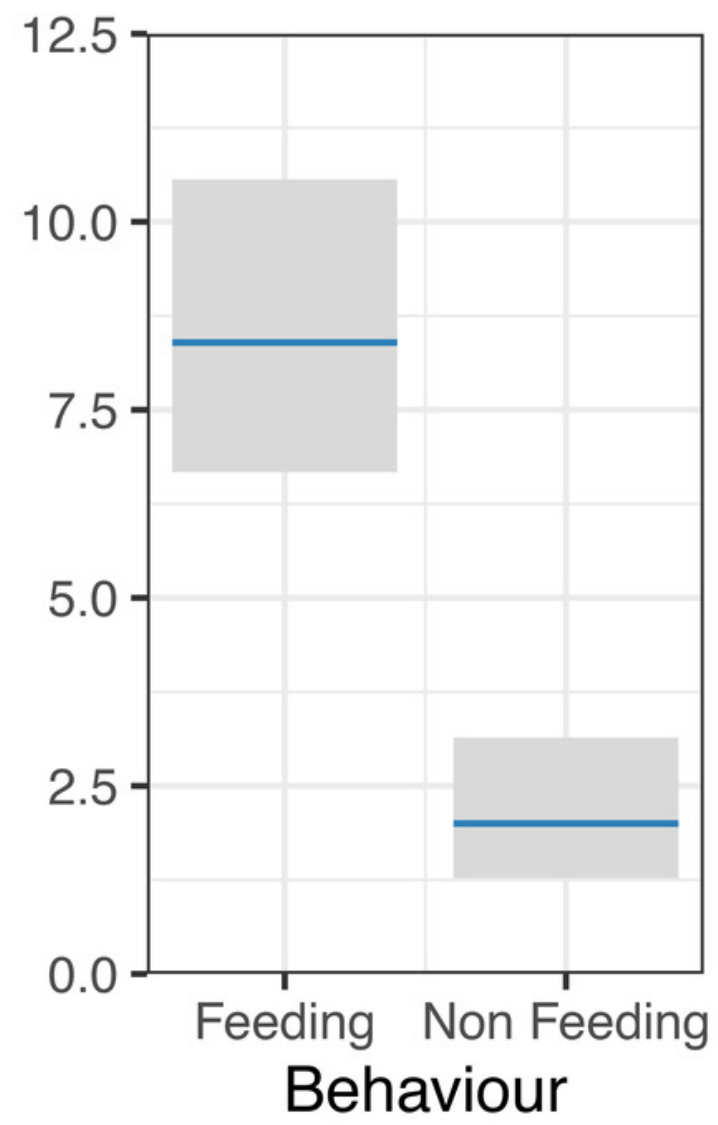




\section{Figure 6}

Zooplankton composition and reef manta ray Mobula alfredi behaviour.

A) Non-metric multidimensional scaling analysis of zooplankton community composition.

Ellipses represent 95\% confidence intervals and broad taxonomic groups are labelled as per their association with manta ray behaviours. B) Undinula vulgaris specimens (Credit: Julian Uribe-Palomino). Percentages of zooplankton community composition in Hanifaru Bay in relation to manta ray behaviour: C) Feeding; and D) Non-feeding. 'Other' comprises taxonomic groups that contributed less than $5 \%$ to the total community composition.

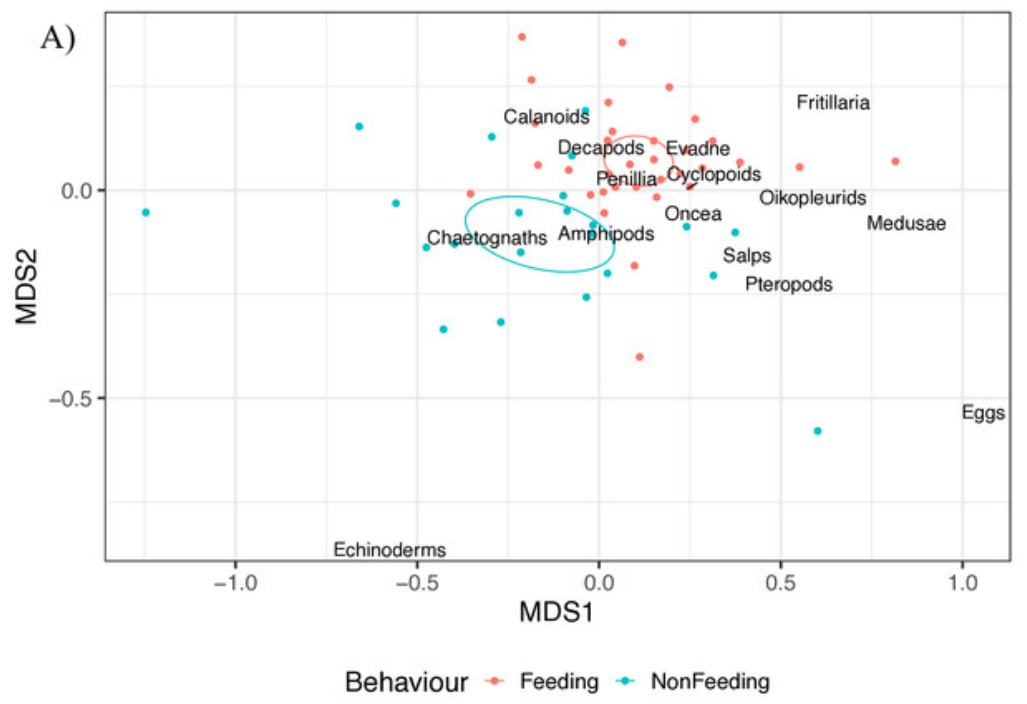

C) Feeding

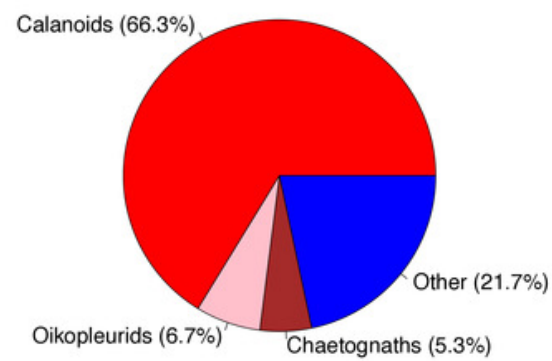

D) Non-feeding

B)

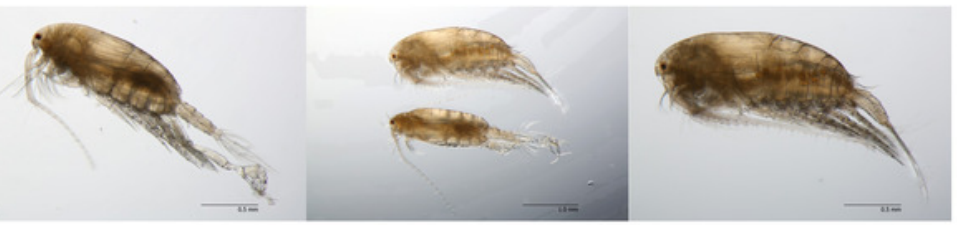

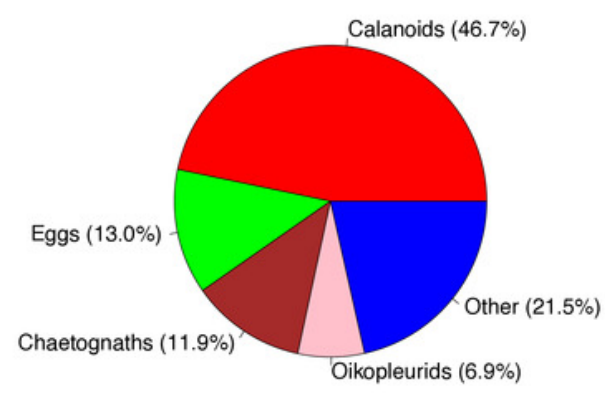




\section{Figure 7}

Zooplankton size structure analysis.

Normalised Biovolume Size Spectra of the zooplankton community when reef manta rays Mobula alfredi are Feeding $(n=33)$ and Non-feeding $(n=22)$. For the $x$-axis, each particle was assigned to one of 50 logarithmic size categories based on its biovolume (Size class). For the $y$-axis, the sum of the biovolume of the particles in each size class $\left(\mathrm{mm}^{3}\right)$ was standardised by the fraction of sample scanned and the volume of water filtered $\left(\mathrm{m}^{3}\right)$, and normalised by dividing this value by the width of the size class measured in biovolume $\left(\mathrm{mm}^{3}\right.$; Normalised biovolume). Dashed lines represent standard error. 


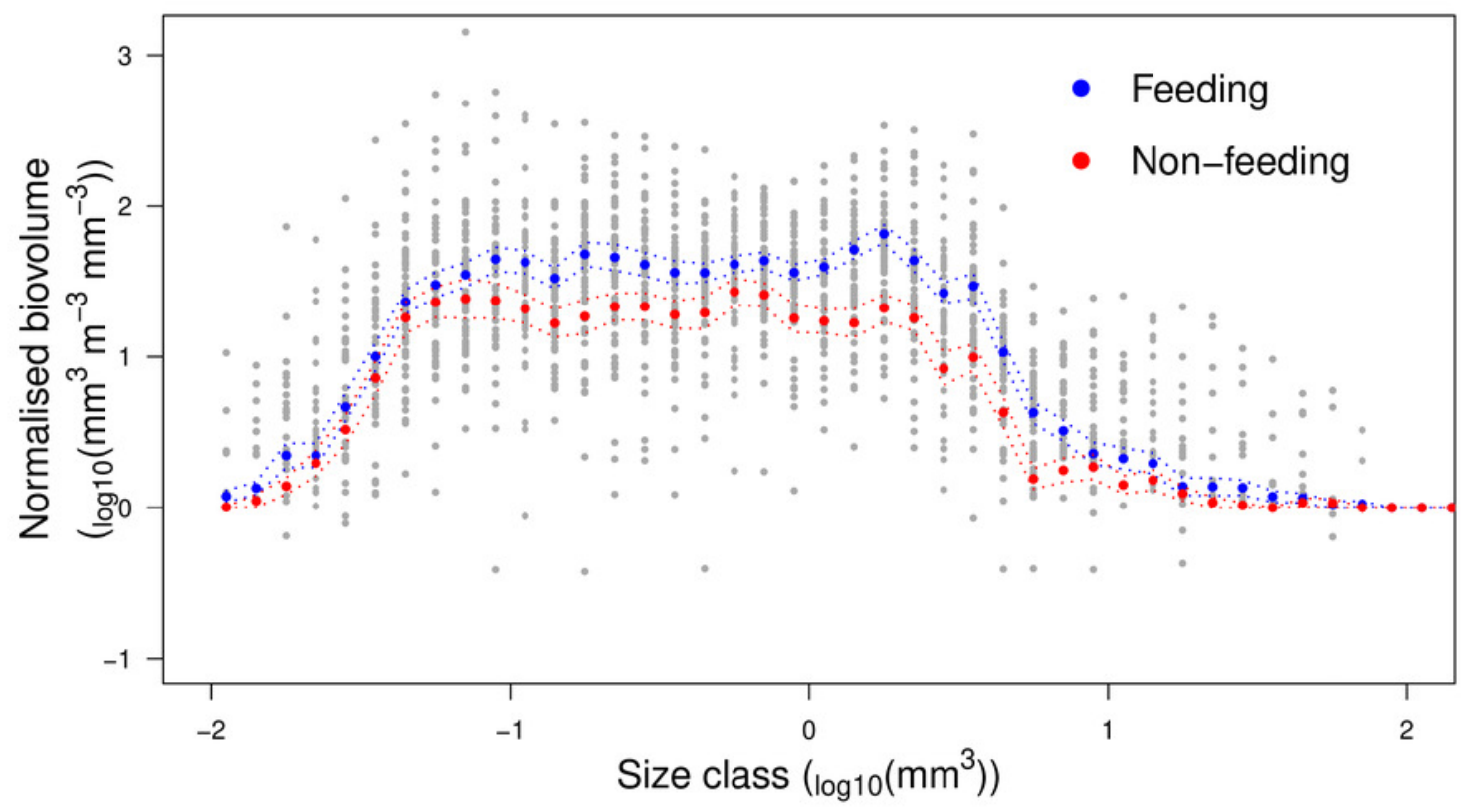

